SOI: $1.1 /$ TAS $\quad$ DOI: $10.15863 / \mathrm{TAS}$ International Scientific Journal Theoretical \& Applied Science

p-ISSN: 2308-4944 (print) e-ISSN: 2409-0085 (online)

Year: $2016 \quad$ Issue: 8 Volume: 40

Published: 30.08.2016 http://T-Science.org
Sergey Alexandrovich Mishchik Associate Professor, Candidate of Pedagogical Science, Corresponding member of International Academy TAS, Assistant professor Department of Physics, State Maritime University Admiral Ushakov, Russia, sergei_mishik@mail.ru

SECTION 21. Pedagogy. Psychology. Innovation in Education.

\title{
FORMATION BENCHMARKS ERTSGAMMING MATHEMATICAL MODELS OF EDUCATIONAL ACTIVITY ASCERTAINS RESEARCH EDUCATIONAL FACILITIES
}

\begin{abstract}
The main directions of analysis of formation benchmarks ertsgamming matematic models of learning activities ascertaining studies of educational facilities on the criteria of life, cycling, systematic and phasing, which form the basic cell education space, as well as the use of the twelve pointed star Ertsgammy for the submission quad-star principle ertsgamming, which will determine the basics of physical pedagogometric through hyperspace shaping of life, psychological and educational activity theory, psycho-pedagogical system analysis and theory formation of mental actions.

Key words: basis property, stating the study, physical pedagogometric, livelihoods, cyclical, systemic, stages, quad-star principle ertsgamming Ertsgammy, educational space.

Language: Russian

Citation: Mishchik SA (2016) FORMATION BENCHMARKS ERTSGAMMING MATHEMATICAL MODELS OF EDUCATIONAL ACTIVITY ASCERTAINS RESEARCH EDUCATIONAL FACILITIES. ISJ Theoretical \& Applied Science, 08 (40): 70-75.

Soi: http://s-o-i.org/1.1/TAS-08-40-14 Doi: crossef http://dx.doi.org/10.15863/TAS.2016.08.40.14
\end{abstract}

УДК 372.851

\section{ФОРМИРОВАНИЕ БАЗИСНЫХ ПОКАЗАТЕЛЕЙ ЭРЦГАММНОСТИ \\ МАТЕМАТИЧЕСКИХ МОДЕЛЕЙ УЧЕБНОЙ ДЕЯТЕЛЬНОСТИ КОНСТАТИРУЮЩЕГО ИССЛЕДОВАНИЯ ОБРАЗОВАТЕЛЬНЫХ ОБЫЕКТОВ}

Аннотация: Рассмотрены основные направления анализа формирования базисных показателей эригаммности математических моделей учебной деятельности констатирующего исследования образовательных объектов относительно критериев жизнедеятельности, ияиклиности, системности и этапности, которые образуют базисную ячейку образовательного пространства, а также применение двенадцати конечной звезды Эригаммы относительно представления квадрозвёдного принципа эригаммности, который определит основы физической педагогометрики через формообразование гиперпространства жизнедеятельности, психолого-педагогической теории деятельности, психологопедагогического системного анализа и теории формирования умственных действий.

Ключевые слова: базисность, констатирующее исследование, физическая педагогометрика, жизнедеятельность, ичиличность, системность, этапность, квадрозвёдный принции эризгаммности, звезда Эриягаммы, образовательное пространство.

Формирование базисных показателей эрцгаммности математических моделей учебной деятельности констатирующего исследования образовательных объектов связывается с поисками в образовательной среде естественного уровня основных проявлений традиционных характеристик образовательной деятельности относительно реализации главных дидактических принципов образования и воспитания субъектов учебного процесса [1].

Построение общей схемы формирования базисных показателей эрцгаммности математических моделей учебной деятельности констатирующего исследования образовательных

ISPC The development of applied research, 
объектов будем соотносить из существования четырёх основных качеств развития широкопрофильной подготовки современных специалистов - критерии жизнедеятельности, цикличности, системности и этапности, которые образуют базисную ячейку образовательного пространства [2].

Критерий жизнедеятельности связывается с существованием принципа эрцгаммности относительно проявления двенадцати качеств гиперпространства жизнедеятельности относительно образовательного процесса: ориентировочная

жизнедеятельность, исполнительная жизнедеятельность, контрольная жизнедеятельность, ориентировочная деятельность, исполнительная деятельность, контрольная деятельность, ориентировочное действие, исполнительное действие, контрольное действие, ориентировочная операция, исполнительная операция, контрольная операция. Материальной моделью данного критерия является двенадцатилучевая звезда Эрцгаммы Звезда гиперпространства жизнедеятельности [3].

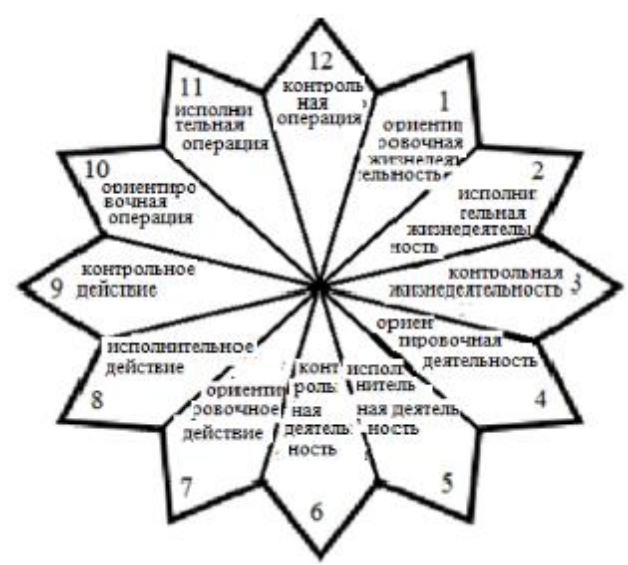

Рисунок 1 - Звезда Эрцгаммы гиперпространства жизнедеятельности.

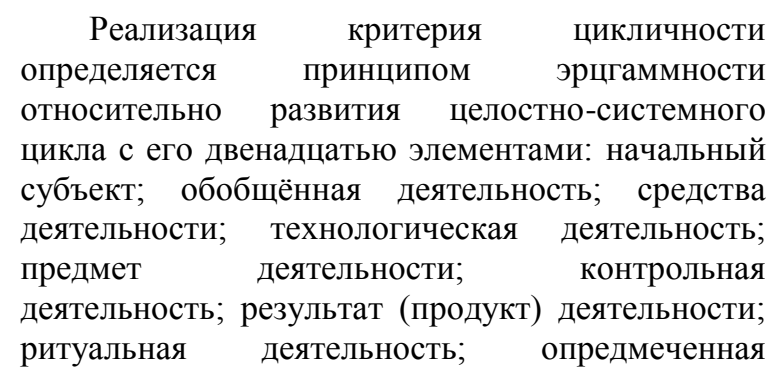

потребность; восходящая деятельность; компаунд-субъект; развивающая деятельность. Результатом этой деятельности является суперсубъект, который открывает последующий цикл развития субъекта жизнедеятельности. Материальной моделью данного критерия является двенадцатилучевая звезда Эрцгаммы Звезда целостно-системного цикла жизнедеятельности [4].

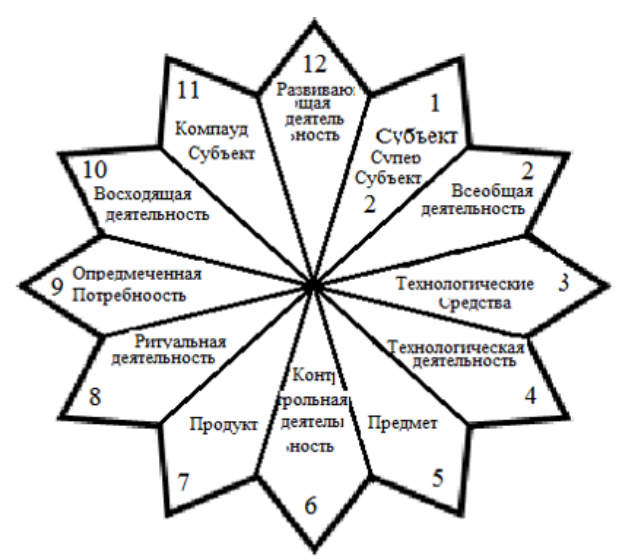

Рисунок 2 - Звезда Эрцгаммы целостно-системного цикла жизнедеятельности.

\section{Критерий системности определяется реализацией принципа эрцгаммности} относительно двенадцати действий системного анализа: выделить объект изучения как систему; определить порождающую среду; установить целостные свойства предмета; представить уровни анализа системы; выделить структуру уровня; определить структурные элементы уровня; установить системообразующие связи уровня; представить межуровневые связи

ISPC The development of applied research, 
объекта; выделить форму организации предмета; определить системные свойства объекта; установить поведение предмета; представить прогноз развития объекта. Выделенная совокупность системных действий составляет

определённую «Азбуку Жизни». Материальной моделью данного критерия является двенадцатилучевая звезда Эрцгаммы - Звезда системного анализа [5,6].

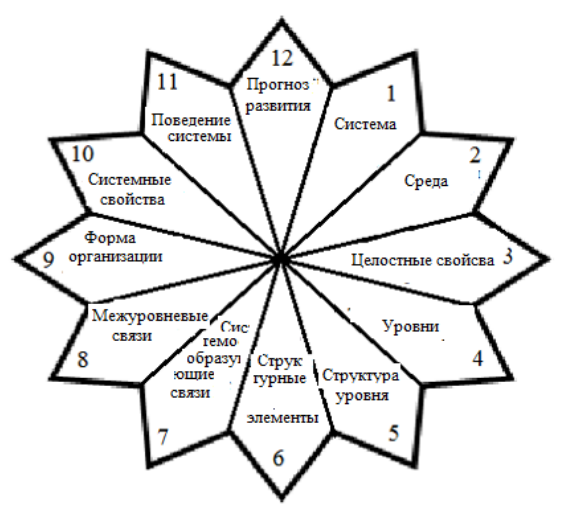

Рисунок 3 - Звезда Эрцгаммы системного анализа.

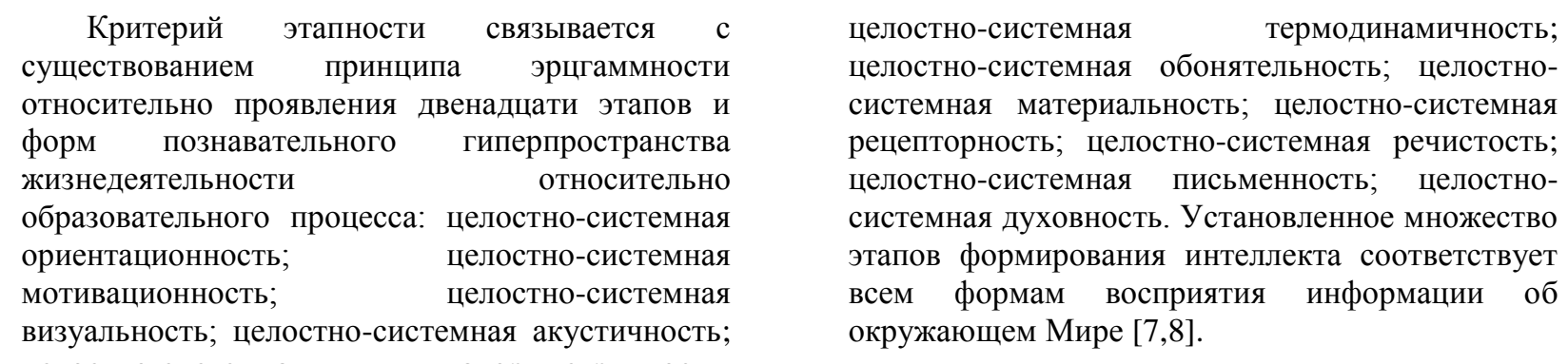
целостно-системная калориметричность;

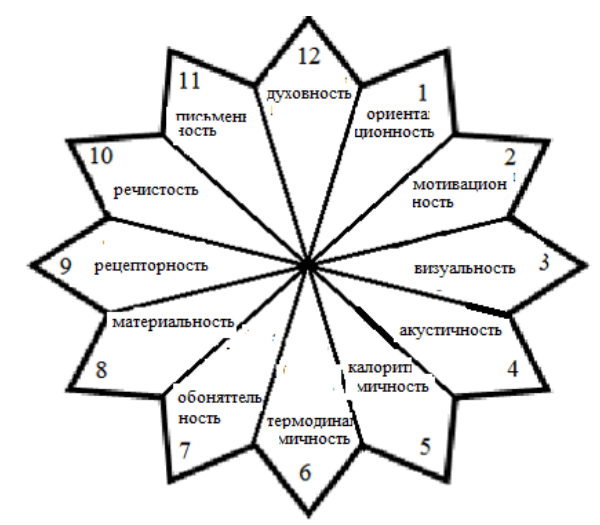

Рисунок 4 - Звезда Эрцгаммы целостно-системных этапов развития интеллекта. 


\begin{tabular}{l|lrl|l|ll} 
& ISRA (India) & $=\mathbf{1 . 3 4 4}$ & SIS (USA) & $=\mathbf{0 . 9 1 2}$ & ICV (Poland) & $=\mathbf{6 . 6 3 0}$ \\
Impact Factor: & ISI (Dubai, UAE) $=\mathbf{0 . 8 2 9}$ & PUHU (Russia) $=\mathbf{0 . 2 3 4}$ & PIF (India) & $=\mathbf{1 . 9 4 0}$ \\
& GIF (Australia) & $\mathbf{0 . 5 6 4}$ & ESJI (KZ) & $=\mathbf{1 . 0 4 2}$ & IBI (India) & $\mathbf{4 . 2 6 0}$
\end{tabular}

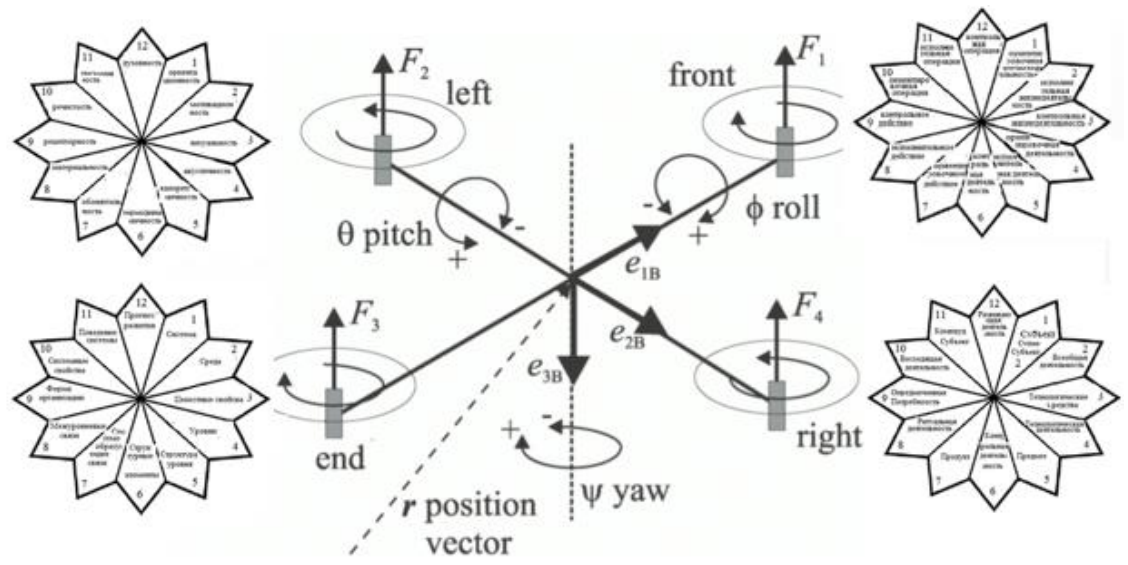

Рисунок 5 - Педагогометрическая модель квадрозвездного принципа эрцгамности.

Взаимодействие

Эрцгаммы можно квадрозвёдного принципа эрцгаммности (Рисунок 5). Представление процесса обучения через квадрокоптерную модель квадрозвёдного принципа эрцгаммности приведёт к введению новых понятий для характеристики учебного процесса, связанного с кинематическими, статическими и динамическими параметрами учебной деятельности. К данным показателям следует отнести: образовательную систему отсчёта в виде учебной программы; координаты учебного материала в форме тематического планирования; линейную скорость учебной деятельности; угловые скорости изменения эрцгаммных характеристик образовательного процесса; массу (массив) учебной информации в виде понятий, отношений, определений, опытных процессов, принципов, постулатов, графических форм, аксиом, теорем, концепций и теорий. Это позволяет определить линейную, поверхностную и объёмную информационную плотность учебного материала. Относительно начала учебной деятельности можно установить важность, базисность, фундаментальность, широкопрофильность учебного материала относительно центра масс информации (акцентированного внимания). Рассматривая быстроту усвоения учебной информации относительно его объёма можно представить импульс образовательной деятельности. Если учесть ускорения нарастания учебной деятельности с совершенствованием схем образовательного процесса, то можно определить меру образовательного взаимодействия между учеником и преподавателем, внутригрупповые и межгрупповые

взаимодействия

образовательном пространстве. Так возникает понятие образовательной силы, когда интенсивность учебно-профессионального отношения изменяется в зависимости от целей и этапов учебной деятельности. С совершенствованием характера самостоятельной работы учащегося изменяется силовое интеллектуальное взаимодействие между всеми компонентами учебного процесса. Кроме этого изменяется и сам вид силового интеллектуального взаимодействия, когда изменяется структура ориентировочного, исполнительного и контрольного образа интеллектуальной деятельности. В целом, это потребует создать основы физической педагогометрики.

Формирование базисных показателей эрцгаммности математических моделей учебной деятельности констатирующего исследования образовательных объектов связывается с выделением сорока восьми параметров процесса обучения, которые отражают четыре базисные эрцгаммности $[9,10]$.

Первая базисная эрцгаммность определяется уровнем существования в экспериментальных учебных группах особенностей жизнедеятельности: ориентировочная жизнедеятельность, исполнительная жизнедеятельность, контрольная жизнедеятельность, ориентировочная деятельность, исполнительная деятельность, контрольная деятельность, ориентировочное действие, исполнительное действие, контрольное действие, ориентировочная операция, исполнительная операция, контрольная операция.

Вторая базисная эрцгаммность задаётся характером целостно-системной цикличности в экспериментальных учебных группах: начальный субъект; обобщённая деятельность; средства деятельности; технологическая деятельность; предмет деятельности; контрольная деятельность; результат (продукт) деятельности; ритуальная деятельность; опредмеченная потребность; восходящая деятельность; компаунд-субъект; развивающая деятельность.

Третья базисная эрцгаммность устанавливается характером системных понятий в экспериментальных учебных группах: выделить объект изучения как систему; определить 
порождающую среду; установить целостные свойства предмета; представить уровни анализа системы; выделить структуру уровня; определить структурные элементы уровня; установить системообразующие связи уровня; представить межуровневые связи объекта; выделить форму организации предмета; определить системные свойства объекта; установить поведение предмета; представить прогноз развития объекта.

Четвёртая базисная эрцгаммность представляется через поэтапность формирования интеллекта в экспериментальных группах: целостно-системная ориентационность; целостно-системная мотивационность; целостносистемная визуальность; целостно-системная акустичность; калориметричность; термодинамичность; обонятельность; материальность; целостно-системная целостно-системная целостно-системная целостно-системная целостно-системная рецепторность; целостно-системная речистость; целостно-системная письменность; целостносистемная духовность.

Формирование межбазисных показателей эрцгаммности математических моделей учебной деятельности констатирующего исследования образовательных объектов устанавливается через выделение прямых и обратных связей между всеми элементами эрцгаммных отношений. Например. Установить характер связи между целостно-системной ориентационностью и целостно-системной мотивационностью; целостно-системной визуальностью; целостносистемной акустичностью; целостно-системной калориметричностью; целостно-системной термодинамичностью; целостно-системной обонятельностью; материальностью; рецепторностью; речистостью; письменностью; духовностью. устанавливается характер связи и с элементами последующих эрцгаммных отношений относительно целостно-системного цикла жизнедеятельности, гиперпространства жизнедеятельности, системного анализа, что и определяет процесс формирования базисных показателей эрцгаммности математических моделей учебной деятельности констатирующего исследования образовательных объектов.

\section{References:}

1. Mishchik SA (2014) Pedagogometrika and mathematical modeling educational activity. Materialy Mezhdunarodnoy nauchnoy konferenctsii "Modern mathematics in science" - 30.06.2014. ISJ Theoretical \&Applied Science 6(14): 54-56 Caracas, Venezuela. doi: http://dx.doi.org/10.15863/TAS.2014.06.14.10

2. Mishchik SA (2014) Simulation training activity methods of mathematical logic. Materialy Mezhdunarodnoy nauchnoy konferenctsii "Eurapean Science and Education" - 30.07.2014. ISJ Theoretical \&Applied Science 6(15): 72-74 Marseille, France. doi: http://dx.doi.org/10.15863/TAS.2014.07.15.13

3. Mishchik SA (2014) Mathematical modeling system integrity-cycle of life activity - first goal pedagogometriki. Materialy Mezhdunarodnoy nauchnoy konferenctsii "European Applied Sciences" - 30.08.2014. ISJ Theoretical \&Applied Science 8(16): 77-79. Aix-en-Provence, France. doi: http://dx.doi.org/10.15863/TAS.2014.08.16.13

4. Mishchik SA (2014) Mathematical modeling system integrity-curricular activities - the second problem pedagogometriki. Materialy Mezhdunarodnoy nauchnoy konferenctsii "European Innovation" - 30.09.2014. ISJ Theoretical \&Applied Science 9(17): 126-128 Martigues, $\quad$ France. doi: http://dx.doi.org/10.15863/TAS.2014.09.17.21

5. Mishchik SA (2014) Mathematical modeling holistic-systemic communicative activity - the third task pedagogometriki. Materialy Mezhdunarodnoy nauchnoy konferenctsii "European Scientific Achievements" 30.10.2014. ISJ Theoretical \&Applied Science 10(18): 45-47 Brighton, UK. doi: http://dx.doi.org/10.15863/TAS.2014.10.18.11

6. Mishchik SA (2014) Mathematical modeling integrity - system performance subject - fourth task pedagogometriki. Materialy Mezhdunarodnoy nauchnoy konferenctsii "European Science and Technology" 30.11.2014. ISJ Theoretical \&Applied Science 11(19): 51-54 Southampton, UK. doi: http://dx.doi.org/10.15863/TAS.2014.11.19.10

7. Mishchik SA (2015) Pedagogometrik - science and academic subject. Materialy Mezhdunarodnoy nauchnoy konferenctsii 


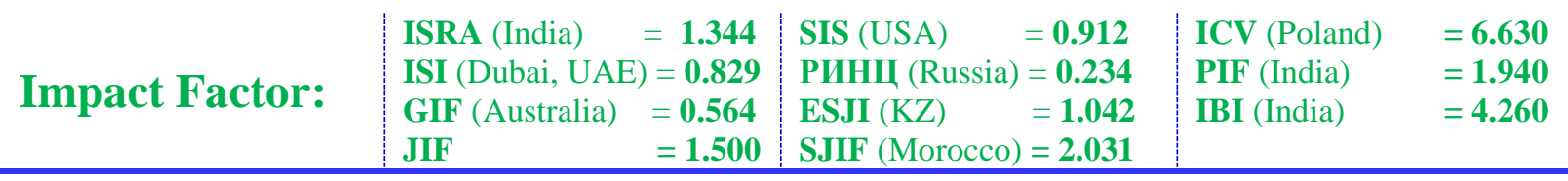

"European Technology in Science" 28.02.2015. ISJ Theoretical \& Applied Science 02 (22): 103-106 Malmö, Sweden. doi: http://dx.doi.org/10.15863/TAS.2015.02.22.17

8. Tokmazov GV (2014) Matematicheskoe modelirovanie $\mathrm{v}$ uchebno-professional'noy deyatel'nosti. Materialy Mezhdunarodnoy nauchnoy konferentsii «Modern mathematics in science» - 30.06.2014. ISJ Theoretical \& Applied Science 6(14): 44-46. - Caracas, Venezuela. doi: http://dx.doi.org/10.15863/TAS.2014.06.14.8

9. Tokmazov GV (2014) Analysis says study skills in the study of mathematics, Materialy Mezhdunarodnoy nauchnoy konferenctsii
"European Science and Education" 30.07.2014. ISJ Theoretical \&Applied Science 6(15): 72-74 Marseille, France. doi: http://dx.doi.org/10.15863/TAS.2014.06.14.

10. Tokmazov GV (2014) Mathematical modeling research skills in educational activity methods of probability theory. Materialy Mezhdunarodnoy nauchnoy konferenctsii "Eurapean Science and Technology" 30.11.2014. ISJ Theoretical \&Applied Science 11(20): 66-69 Southampton, United Kingdom. doi:

http://dx.doi.org/10.15863/TAS.2014.11.19.13 